\title{
Antioxidant Potential of Silver Nanoparticles Synthesized from Beta (1-3) Glucan Isolated from the Edible Mushroom Pleurotus florida ${ }^{\dagger}$
}

\author{
C.R. Meera ${ }^{1, *}$, Nisha Peter ${ }^{1}$ \\ 1 Department of Microbiology, St Mary's College, Thrissur-20, Kerala, India \\ * Correspondence: meeramaheswaran2005@gmail.com; \\ $\dagger$ Presented at International e-Conference on Bioengineering for Health and Environment (ICBHE 2020)
}

Received: 5.07.2020; Revised: 10.07.2020; Accepted: 12.07.2020; Published: 15.07.2020

\begin{abstract}
Pleurotus florida of the genus Pleurotus, is a delicious edible mushroom with high therapeutic potential and is being cultivated extensively in many parts of the world, including India. Polysaccharides, especially $\beta$-glucans, are the most potent mushroom derived metabolites. Silver nanoparticles (AgNPs) are gaining a lot of importance nowadays because of their wide industrial and biomedical applications. In the present investigation, silver nanoparticles were synthesized using $\beta$ glucan isolated from the fruiting bodies of $P$. florida and their antioxidant properties were studied. Polysaccharide (PS) isolation was carried out by hot water extraction, deproteinization, alcohol precipitation, centrifugation, and dialysis. Preliminary characterization of isolated polysaccharide was done by the Anthrone method, Lowry's method, Thin Layer Chromatography (TLC), and FT-IR. The PS was treated with $\mathrm{AgNO}_{3}$ solution $(0.001 \mathrm{M})$ for the biosynthesis of silver nanoparticles, and nanoparticle formation was confirmed by UV spectroscopy. Antioxidant properties of the PS, as well as synthesized nanoparticles, were evaluated using Total antioxidant capacity assay, DPPH-Free radical scavenging assay, Total reducing power assay, and Hydroxyl radical scavenging assay. Preliminary characterization showed that the isolated PS is protein-bound $\beta$ (1-3) Glucan. Both the PS and silver nanoparticles showed profound antioxidant activity in a dose-dependent manner. In all assays, silver nanoparticles showed more activity than the PS. The highest activity was shown in Hydroxyl radical scavenging assay in which PS and nanoparticles showed $81.8 \%$ and $89.4 \%$ activity, respectively, at the highest tested dose of $2000 \mu \mathrm{g}$. The present study reveals the possibility of $\beta$-glucan -silver nanoparticles from $P$. florida as a suitable candidate for antioxidant drug development.
\end{abstract}

Keywords: Polysaccharides; Silver nanoparticles; P. florida; antioxidant; $\beta$ (1-3) Glucan.

(C) 2020 by the authors. This article is an open-access article distributed under the terms and conditions of the Creative Commons Attribution (CC BY) license (https://creativecommons.org/licenses/by/4.0/).

\section{Funding}

This research received no external funding.

\section{Acknowledgments}

This research has no acknowledgment.

\section{Conflicts of Interest}

The authors declare no conflict of interest. 